Revista de la red interuniversitaria de estudios sobre las literaturas rioplatenses contemporáneas en Francia

16 | 2017

Esnobismos

\title{
Ambiguas transparencias
}

\section{Julio Premat}

\section{OpenEdition}

\section{Journals}

\section{Electronic version}

URL: http://journals.openedition.org/lirico/3772

DOI: $10.4000 /$ lirico.3772

ISSN: 2262-8339

\section{Publisher}

Réseau interuniversitaire d'étude des littératures contemporaines du Río de la Plata

\section{Electronic reference}

Julio Premat, «Ambiguas transparencias », Cuadernos LIRICO [En línea], 16 | 2017, Puesto en línea el 07 octubre 2017, consultado el 20 abril 2019. URL : http://journals.openedition.org/lirico/3772 ; DOI 10.4000/lirico.3772

This text was automatically generated on 20 April 2019

\section{(c) $($ ) $(9)$}

Cuadernos LIRICO está distribuido bajo una Licencia Creative Commons Atribución-NoComercialSinDerivar 4.0 Internacional. 


\section{Ambiguas transparencias}

Julio Premat

\section{REFERENCES}

Chejfec, Sergio. Teoría del ascensor. Zaragoza: Jekyll \& Jill, 2016, 221 p. 
1 En los últimos años, además de relatos, Sergio Chejfec ha publicado varios libros de ensayos, sea como sea que se defina el ensayo o cualquier cosa que eso signifique, para retomar un habitual giro discursivo de sus textos, giro que, como se dice, «lo pinta entero» al escritor (a su posición ante los enunciados y certezas, al transparente y sin embargo dudoso tono utilizado) ${ }^{1}$. Ha publicado entonces, decía, varios libros de ensayos: después de $E l$ punto vacilante, ya lejano (2005), Sobre Giannuzzi en el 2010, Últimas noticias de la escritura en el $2015 \mathrm{y}$ Teoría del ascensor en el 2016 se suceden. La novedad es en alguna medida editorial, ya que Chejfec siempre escribió textos ensayísticos, empezando por algunas notables reseñas en la revista Babel en los años 80; con todo la reciente acumulación

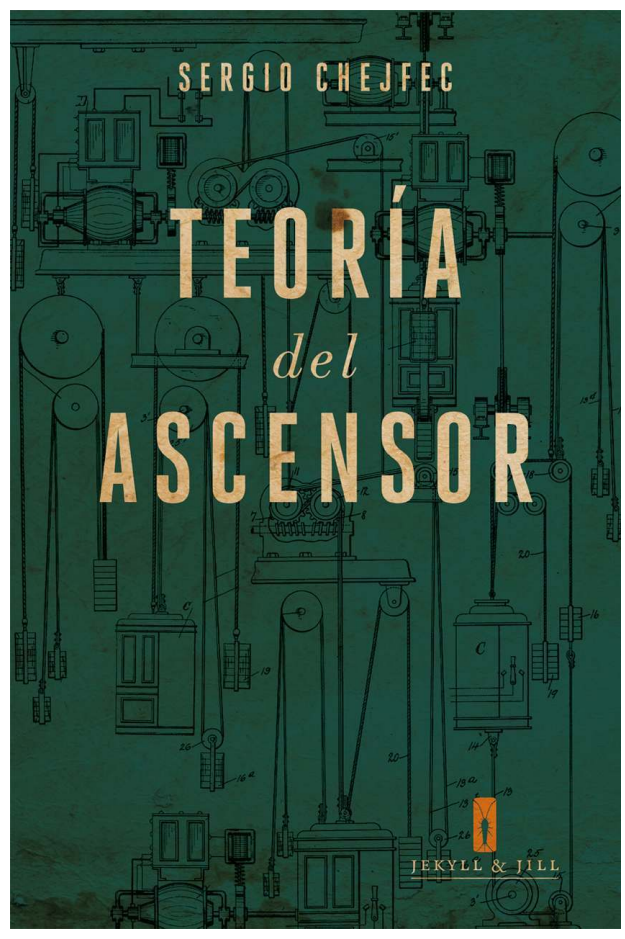
produce un efecto de lectura, el de acentuar y volver más perceptible una concepción de la literatura y una práctica singular de escritura.

2 No resulta del todo sencillo resumir o sintetizar Teoría del ascensor -quizás un poco menos que otros libros de Chejfec-, compuesto como está por una serie de textos breves, sin título, que a veces constituyen series en la medida en que dialogan unos con otros. Muchos, lo sospechamos o lo sabemos, fueron presentados y/o prepublicados como unidades independientes. Sin embargo, la discreta pero operativa organización de fragmentos de épocas y temas distintos, separados por sobrios asteriscos, crea efectos de ritmo y de resonancia que poco tienen que ver con una visibilidad temática que se organizaría en polos coherentes. A ojos vista, la «instalación» en el orden sucesivo del libro está percibida como un acto, si no de escritura, al menos de creación, según la repetida atracción de Chejfec por los dispositivos como una manera de producir resultados a la vez mecánicos e inhabituales.

Efectivamente, el lector (o más bien el «relector» que piensa escribir una reseña y trata por lo tanto de proponer una visión sintética), reconoce series temáticas que podrían haber sido agrupadas en armoniosas secciones: la ciudad y los lugares del escritor, esos «sucedáneos» (p. 172) de la subjetividad (una y otra vez nos paseamos por Caracas, por Buenos Aires, por Nueva York, por Boston, por domicilios y talleres de artistas, a veces interrogativamente, a veces con nostalgia); el valor de lo documental, la referencialidad o la materialidad en la literatura, cuando no del original; los efectos de la traducción y del bilingüismo como borrado de una matriz primera y como desplazamiento productivo; la representación afable y tenue de una comunidad (muchos, la mayoría de los textos consisten en o parten de charlas con amigos escritores o artistas); la atracción por las instalaciones, los dispositivos lúdicos, los desplazamientos formales (la invención de una lista de concordancia entre platos de comida y escritores argentinos, una investigación en las guías de teléfono viejas buscando domicilios de autores, un paralelismo entre los ascensores y los actos de lectura/escritura); y, de manera más previsible en un libro de 
ensayos de escritor, comentarios sobre autores, cineastas, artistas; los dedicados a Mercedes Roffé, Di Benedetto, Béla Tarr, Igor Barreto, Victoria de Stefano, Saer, Sebald, son los más extensos, pero muchos otros nombres circulan en el libro: Kluge, Osvaldo Lamborghini, Kipling, Cortázar, Tanizaki, Bellatin, Caparrós, Carlos Ríos, Aira. A cada uno de estos aspectos, e incluso a algunos autores, se vuelve una y otra vez (por ejemplo, tres textos sobre Roffé o tres otros sobre traducción, separados y cuidadosamente situados en el enigmático orden del libro). Por lo tanto, el intento de reorganización sintética del contenido está condenado al fracaso, aunque más no sea porque las series se superponen: una charla sobre lecturas durante el recorrido de un espacio urbano en la que se especula sobre lo material o sobre la experiencia seguramente existe -habría que verificarlo- en el libro.

4 Los primeros textos, los más breves, comentan la ausencia de un sentido global («Terminada la lectura y a punto de cerrar el libro aún ignorantes de qué se ha tratado...» es el íncipit de Teoría del ascensor; y el segundo texto insiste: «Acabo de cerrar el libro y no entiendo muy bien de qué ha tratado») (p. 7-8). El horizonte de no significancia así dispuesto permite acercarse digamos sin expectativas a las anécdotas, todas en relación con lo artístico, que se van hilvanando en lo que sigue. Sin embargo, y a falta de un índice lógico, podríamos recurrir al «Índice alfabético final» para crearnos itinerarios de lectura, aunque esta opción se topa con otro dispositivo de carácter digamos paródico: en la lista figuran todos los nombres propios mencionados en el libro, sin distinción. 0 sea que allí se incluyen las iniciales que en muchos textos y aleatoriamente disimulan los nombres verdaderos (un/una tal MG, se pone a pensar uno, pareciera remitir a Graciela Montaldo con una inversión de sus iniciales -al menos que Montaldo se llame en realidad María Graciela-; mientras que CG actúa y piensa como si fuese el mismísimo Chejfec, etc.), llevando a cabo una de las operaciones más claras de «desrealización» y de toma de distancia ficcional frente al género ensayo. $\mathrm{Y}$ ese índice alfabético también incorpora nombres irrelevantes: una bomba de gasolina Esso, algunas calles de varias ciudades mencionadas al pasar, una panadería porteña, un videoclub caraqueño. La lista pareciera haber sido establecida por una función de procesamiento de texto, sin intervención posterior o sin intencionalidad autoral que jerarquice su contenido.

5 Ahora bien, si me detengo en lo que sería una escritura «material» (en el sentido de una ubicación de lo escrito) es porque me parece obedecer a una serie de posiciones e incluso obsesiones que, una y otra vez, se ponen de manifiesto: la atracción por la ambigüedad y por lo indefinido, los interrogantes repetidos sobre la experiencia y su transmisibilidad, la tensión entre los esquemas y formas (como los mapas) y lo documental, el lugar en el que se esbozaría la presencia de un original o inclusive de un origen.

6 Tarea ardua en todo caso resumir el libro, pero a fin de cuentas quizás haya un aspecto que domina -sin querer, claro está, situarlo en el centro ni establecer jerarquías al respecto-. Se trata de un recorrido por el lugar del que escribe, ante todo porque se expande una voz que, más cerca del yo del escritor (inherente al tono ensayístico), pero sin diluirse en él, pasa sin muchos cambios de los libros de ficción a estos textos híbridos. Al mismo tiempo, la delimitación indirecta de una concepción de la literatura o la prolongación de la propia literatura con un desplazamiento a libros ajenos, a prácticas, a experiencias muchas veces mínimas, refuerza la impresión de una doble referencialidad: con respecto a temas o a autores tratados por un lado, a la propia obra y escritura por el otro. No creo, de ninguna manera, que se trate de una especificidad de Teoría del ascensor porque la visión interrogativa sobre lo escrito, la transmisión de una intriga adelgazada 
hasta la invisibilidad y las puestas en escena de una peculiar primera persona (o de un personaje en el que se focaliza el relato) son características de buena parte de la producción de Chejfec, en particular de sus últimos libros de ficción (pienso en $L a$ experiencia dramática o en Modo linterna). Simplemente, en esta «silva de varia lección» se acentúan, por su heterogeneidad, algunos rasgos presentes en otros libros.

7 La autorrepresentación, si la hay, y los interrogantes que la acompañan, se inscriben en la esfera de la negatividad y de la desconfianza. Porque si en el libro aparecen una voz, un tipo de escenas, ciertas obsesiones, cierto tipo de juicios, la omnipresencia de un modo Chejfec (entendiendo modo como una expansión del estilo a esferas más amplias que engloban al sujeto y que incluyen lo enigmático del proceso), ese modo se sitúa más o menos en los antípodas del egocentrismo de buena parte de la literatura contemporánea. En vez de una prolongación de la «literatura del yo» estamos ante una representación que tiende a una anulación del sujeto. Una «nadería de la personalidad», se dirá, recordando al juvenil Borges, o el «escritor no es nada, nadie» de Saer; sin embargo, poco queda en Chejfec del oximorónico mesianismo borgeano o del lirismo epifánico de un yo fisurado saeriano. Se trata, más bien, de proponer una asociación entre escrituras «medio subjetivizadas y documentacionales», ya que la integración de lo documental es la «única opción literaria posible» para que la narración de experiencias de una primera persona «mantenga una presencia no amenazada por la irrelevancia» (p. 22). A ojos vista, la voz se define por la distancia que toma consigo misma, alejándose de cualquier «matriz confesional» (p. 49), renunciando a ser la «única involucrada en saber lo que hay que poner o no» (p. 77); una voz que busca una concepción alternativa del lirismo, como la que se lee en Roffé, un lirismo que «colme nuestra sensibilidad sin propinarnos efusiones sentimentales» (p. 89); una voz que paradójicamente se despoje de cualquier «hondura psicológica» y que, gracias a ese gesto, sintonice «con cierto solipsismo subjetivo» (p. 128). En lo dicho circula una idea, utópica, que es la de un borrado de sí mismo para ser otro, la de una inexistencia; ser «alguien que ha amanecido a la vida esta misma mañana» y pasa por lo tanto a ser «un miembro hasta entonces desconocido, recién llegado, como alguien sin ostensibles ataduras con el pasado» (p. 94). A falta de poder instalarse en esta extranjería absoluta, el borrado sirve de autodefinición: «lo mío es estar fuera» (p. 180).

Frente a las operaciones alrededor de una «figura de autor» en términos institucionales, denostada, la obra y los ensayos de Chejfec se inscriben así en la órbita de una literatura dubitativa, en la que se defiende una «indecisión» que, frente a las cosas que son «demasiado transparentes», «torna ambigua la situación» (p. 41). Sus libros no quieren decir nada en particular, «tan solo aludir a una serie, por otra parte un poco amplia, de cuestiones» (p. 97) o dirimir «reyertas de baja intensidad» (p. 103). Su obra, aunque especulativa, no revela nada: «La literatura habla, cuando tiene la oportunidad, del problema y de la revelación, pero no los descubre» (p. 120). Este rechazo es, sin duda, el único terreno en el que encontramos, sorprendentemente, afirmaciones excluyentes: «Porque así como detesto ver la realidad organizada como literatura, desprecio lo claro y lo explícito, las pretendidas formas de lo verdadero que buscan imponerse como tales» (p. 95). Esas cuestiones, esos interrogantes no tienen, valga la repetida analogía, la dimensión cósmica de las preguntas planteadas por la obra de Borges, ni comprometen el destino de un sujeto que está en el borde de un hundimiento melancólico o de una revelación negativa, como en Saer. No hay nada épico en Chejfec, ni siquiera en el descreimiento o en la desconfianza ante el sentido, la verdad, lo afirmativo. Apenas, y esto quizás es relativamente nuevo con respecto a textos anteriores, una sutil nostalgia 
(«Entonces no queda nada, cada acción surge autónoma, independiente del entorno. Y así los años se escurren») (p. 38).

9 En algunas de las citas y resúmenes que acabo de hacer leo comentarios sobre otros artistas o sobre espacios reales como afirmaciones del escritor sobre sí mismo, es decir que interpreto las repeticiones como obsesiones y los juicios generales como esbozos de un programa personal. Así como sucede con la nostalgia (en particular por los años vividos en Caracas o por la muy presente Buenos Aires), algo similar se produce en la relación de Chejfec con su propio proyecto: los años llevan a proponer una mirada que finalmente, si bien no es normativa, termina siendo explicativa. Como en tantos ensayos de escritores, es inevitable entonces leer estos textos a partir de una doble referencialidad (sobre el tema tratado por un lado, sobre la propia obra por el otro) aunque, repito, en este caso no se instala una perspectiva programática estricta (hablar de los otros para identificar lo que en ellos confirma las certezas de la propia escritura) sino interrogativa: buscar en los otros aquello que permite entender o al menos enunciar, trabajosamente, las endebles características de lo propio. No hacer de los otros proyecciones narcisistas del yo (como Borges y Saer en sus citas y ensayos), sino esbozar un autorretrato en aguas ajenas, a pesar de la corriente que las empuja y de los torbellinos que perturban su limpidez. No escribir porque se ha leído, sino leer para, aunque sea fugazmente, haber escrito. Lo mismo sucede con la experiencia: la repetida evocación de ciudades y momentos compartidos con amigos no son la reconstrucción mnemónica de lo vivido, sino la búsqueda, gracias a ellos, de una impresión incierta de haber vivido.

Todo esto no deja de ser contradictorio, a veces, con ciertos postulados: la levedad incrédula, que es la característica mayor de la escritura de Chejfec, está matizada por una adhesión sin fallas, plena, apasionada, pero nunca declarativa o histriónica, a la literatura (así como a ciertos espacios amados o a la amistad, sin ir más lejos). A pesar de esa incredulidad, leemos la reivindicación de una curiosidad intermitente y de una experimentación artística siempre por hacerse (así, el futuro sigue existiendo). La incredulidad tampoco impide el aura mágica de muchas páginas del libro, páginas que rehúsan burlonamente y de antemano cualquier resumen encasillante. Esta resistencia también contamina lo evaluativo: decir que Teoría del ascensor es un libro extraordinario sería contradictorio con la idea de la literatura y del lenguaje que en él se exponen, literatura y lenguaje alejados de una potencia expresiva (aquí, la del exceso ditirámbico). En el claroscuro desde el que escribe Chejfec no hay espacio para ese tipo de afirmaciones tajantes. Valgan estas negaciones y precauciones oratorias para subrayar la paradójica intensidad de Teoría del ascensor, o sea para invitar a la lectura de este libro ordinario y fuera de lo común.

\section{NOTES}

1. Un ejemplo leído en Teoría del ascensor: "que la obra -cualquier cosa que ahora esto quiera decir- sólo perdure -cualquier cosa que esto quiera decir también- a través de la traducción..." (p. 76). 


\section{AUTHORS}

\section{JULIO PREMAT}

Laboratoire d'Etudes Romanes, Université Paris 8. 